\title{
Management of incidentally discovered intracranial vascular abnormalities
}

\author{
Nohra Chalouhi, M.D., Aaron S. Dumont, M.D., Ciro Randazzo, M.D., \\ Stavropoula TJoumakaris, M.D., L. Fernando Gonzalez, M.D., \\ Robert Rosenwasser, M.D., and Pascal Jabbour, M.D. \\ Department of Neurosurgery, Thomas Jefferson University and Jefferson Hospital for Neuroscience, \\ Philadelphia, Pennsylvania
}

\begin{abstract}
With the widespread use of brain imaging studies, neurosurgeons have seen a marked increase in the number of incidental intracranial lesions, including vascular abnormalities. Specifically, the detection of incidentally discovered aneurysms, arteriovenous malformations, cavernous angiomas, developmental venous anomalies, and capillary telangiectasias has increased. The best management strategy for most of these lesions is controversial. Treatment options include observation, open surgery, endovascular procedures, and radiosurgery. Multiple factors should be taken into account when discussing treatment indications, including the natural history of the disease and the risk of the treatment. In this article, the authors focus on the natural history of these lesions and the risk of the treatment, and they give recommendations regarding the most appropriate management strategy based on the current evidence in the literature and their experience with intracranial vascular abnormalities. (DOI: 10.3171/2011 9.FOCUS11200)
\end{abstract}

$\begin{aligned} & \text { KEY WORDS } \\ & \text { developmental venous anomaly }\end{aligned}$
$\bullet \quad \begin{gathered}\text { aneurysm } \\ \text { capillary telangiectasia }\end{gathered}$$\quad \begin{gathered}\text { cavernous angioma } \\ \text { incidental finding }\end{gathered}$

$\mathrm{B}$ RAIN vascular abnormalities including aneurysms, AVMs, CAs, DVAs, and capillary telangiectasias are common incidental findings on imaging studies. With brain imaging becoming available ubiquitously, these common lesions are expected to be discovered more and more in an asymptomatic stage. The management of most of these vascular abnormalities is still controversial. As a general rule, the natural history of these lesions should be balanced against the risk of morbidity and mortality that may result from treatment. With the conflicting results of recent studies, uncertainty remains concerning the natural history and the risk of treatment, further complicating the neurosurgeon's task. This article reviews the current evidence in the literature regarding the management of incidentally discovered aneurysms, AVMs, CAs, DVAs, and capillary telangiectasias and provides neurosurgeons with a decision-making paradigm for each of these lesions.

\footnotetext{
Abbreviations used in this paper: ARUBA = A Randomized Trial of Unruptured Brain AVMs; AVM = arteriovenous malformation; $\mathrm{CA}=$ cavernous angioma; $\mathrm{DVA}=$ developmental venous anomaly; ISUIA = International Study of Unruptured Intracranial Aneurysms; SAH = subarachnoid hemorrhage.
}

\begin{abstract}
Aneurysms
The management of unruptured intracranial aneurysms has been a very controversial topic in neurosurgery. There is no clear consensus today as to when an incidental aneurysm should be treated and when it should be observed. Moreover, the magnitude of this problem is expected to increase in the future commensurate with increased detection due to advances in imaging quality and availability. The prevalence of aneurysms in the general population is thought to be somewhere between $1 \%$ and 7\%..$^{63,67,102,118}$ However, aneurysmal SAH remains a rare event with an incidence of 6-20 cases per 100,000 persons per year. ${ }^{49,60,92}$ This underscores the importance of patient selection for treatment. Because most aneurysms remain asymptomatic throughout the patient's life, it is crucial to weigh the risks of treatment against the natural history of these lesions. Treatment should only be offered to patients whose risk of SAH exceeds the risk of surgical or endovascular intervention.
\end{abstract}

\section{Natural History}

The natural history of intracranial aneurysms continues to be a controversial topic mainly because of the con- 
flicting results of the different studies. The largest study to date that evaluated the risk of rupture of intracranial aneurysms is the ISUIA (International Study of Unruptured Intracranial Aneurysms). ${ }^{58,147}$ This prospective study involved 1692 patients and reported 5-year rupture rates for anterior circulation aneurysms with respect to their size as follows: $0 \%$ for lesions smaller than $7 \mathrm{~mm}$ in diameter, $2.6 \%$ for those $7-12 \mathrm{~mm}, 14.5 \%$ for those $13-24 \mathrm{~mm}$, and $40 \%$ for those larger than $25 \mathrm{~mm}$. The annual rate of SAH was $0.05 \%$ for aneurysms less than $10 \mathrm{~mm}$ in diameter and $1 \%$ for those $10 \mathrm{~mm}$ or greater. The 5-year rupture rates for posterior circulation aneurysms (including posterior communicating artery aneurysms) were $2.5 \%$ for those less than $7 \mathrm{~mm}, 14.5 \%$ for those $7-12 \mathrm{~mm}, 18.4 \%$ for those 13 $24 \mathrm{~mm}$, and $50 \%$ for those larger than $25 \mathrm{~mm}$. Results also showed that the relative risk of rupture was 11.6 for aneurysms $10-24 \mathrm{~mm}$ in diameter and around 13 for posterior circulation aneurysms. Thus, the size and the location of the aneurysms are 2 important factors in predicting the risk of rupture of these lesions. Patients with a history of SAH from another aneurysm were found to have an annual risk of rupture of $0.5 \%$, which is substantially higher than the risk for patients with no history of SAH $(0.05 \%)$. Despite being heavily criticized by many authors for the flaws in the design, as well as a significant selection bias, the ISUIA has challenged the reports of previous studies and has had an enormous impact on the contemporary management of intracranial unruptured aneurysms. Based on the results of this study, the Stroke Council of the American Heart Association published guidelines for the management of unruptured aneurysms favoring observation over treatment for aneurysms less than $10 \mathrm{~mm}$ in diameter. ${ }^{19}$ They also recommended special consideration for treatment of small aneurysms approaching the 10-mm-diameter size, those with daughter sac formation, patients with a positive family history for aneurysms or aneurysmal $\mathrm{SAH}$, and if changes in aneurysmal size or configuration are observed. ${ }^{19}$

In contrast to the findings of the ISUIA, several studies have reported results showing that the majority of SAH resulted from aneurysms less than $10 \mathrm{~mm}$ in size. ${ }^{21,34,70}$ Winn et al. ${ }^{150}$ found that $80 \%$ of aneurysmal SAH resulted from aneurysms that were smaller than $10 \mathrm{~mm}$ in their greatest diameter. They also suggested that the yearly rate of rupture of intracranial aneurysms falls between $1 \%$ and $2 \%$. Similarly, in a study from Finland that followed 142 patients with 181 unruptured inrtracranial aneurysms for a period of 19.7 years, the overall annual incidence of $\mathrm{SAH}$ was found to be $1.3 \%$ in patients with prior $\mathrm{SAH}$ and $1 \%$ in those with incidental aneurysms. ${ }^{68} \mathrm{~A}$ recent meta-analysis that included 19 studies with 4705 patients and 6556 unruptured aneurysms showed an annual risk of rupture ranging from $0.6 \%$ to $1.3 \% .^{146}$ These results were significantly higher than the annual risk of rupture reported by the ISUIA. The meta-analysis also identified higher age, female sex, smoking, location at the posterior circulation, and increasing size of the aneurysm as risk factors for SAH. In our practice, most patients present with SAH harbor aneurysms smaller than $10 \mathrm{~mm}$, and a significant proportion present with ruptured aneurysms less than $5 \mathrm{~mm}$ in diameter.

\section{Risk Associated With Treatment}

The 30-day rate of mortality from aneurysmal SAH approaches 50\%. ${ }^{14,56}$ Preventive treatment of the aneurysm can avoid this deadly and profoundly disabling event. Treatment of unruptured aneurysms can be achieved either by surgical clipping or by endovascular means. In either case, the risk of the intervention should be weighed against the potential benefit because the rate of morbidity and mortality is substantial with these procedures. ${ }^{17,54,58,114,147}$ The ISUIA reported a combined morbidity and mortality rate at 1 year equal to $12.2 \%$ for surgery and $9.5 \%$ for coil embolization. ${ }^{58,147}$ Many studies have reported, however, a better benefit-risk profile for endovascular techniques than for surgery. ${ }^{54,64,65}$ In a series of 2069 patients with unruptured aneurysms, Johnston and colleagues ${ }^{65}$ found that adverse outcomes were more frequent in patients treated with surgery $(25 \%)$ than in those treated with endovascular procedures. In a recent large study that evaluated 2535 unruptured aneurysms, endovascular treatment was associated with fewer adverse outcomes (6.6\% vs $13.2 \%$ ) and decreased mortality ( $0.9 \%$ vs $2.5 \%)$ than surgical treatment. ${ }^{54}$ Many studies published recently have noted a very low rate of complications or death related to aneurysm treatment. Moroi et al. ${ }^{97}$ reported a remarkable $0.3 \%$ mortality and $2.2 \%$ morbidity after treating 549 unruptured aneurysms. In a recent report Benes and colleagues ${ }^{20}$ suggested that unruptured aneurysms can be treated with coil embolization with low rates of complication (6-month combined morbidity and mortality rate of $1.5 \%$ ), justifying offering treatment to most patients with unruptured aneurysms. Along similar lines, surgical treatment has produced low rates of morbidity and mortality in patients with unruptured aneurysms in expert hands. ${ }^{5,108,109,123,141}$ Tuffiash et al. ${ }^{141}$ demonstrated no cognitive effects of craniotomy for unruptured aneurysms. Furthermore, the unparalleled team of Dr. Charles Drake and colleagues was able to clip unruptured basilar bifurcation aneurysms smaller than $12.5 \mathrm{~mm}$ in diameter with a $3.6 \%$ risk of poor outcome and no mortality. ${ }^{108}$ Later in their monumental series, the combined risk of morbidity and mortality was reduced below $3 \%$. Therefore, it is clear that the rate of morbidity and mortality of microsurgery or endovascular techniques is largely dependent on the experience of the neurosurgical team.

\section{Management of Incidentally Discovered Aneurysms}

Neurosurgeons should consider many factors before deciding whether to treat or watch an incidentally discovered aneurysm. If the risk of SAH is substantial, treatment should be considered. Two important factors that help predict the risk of rupture are the size and the location of the aneurysm. Aneurysms larger than $10 \mathrm{~mm}$ and those located in the posterior circulation are at increased risk of rupture. ${ }^{58,147}$ Conversely small intracavernous internal carotid artery aneurysms are less prone to rupture and do not lead to SAH; observation is therefore recommended for these lesions. ${ }^{19}$ Many studies also showed that multilobed aneurysms are at increased risk of hemorrhage compared with single-lobed lesions. ${ }^{14,122}$ Another parameter that showed association with the risk of rupture is the aspect ratio (height/neck width). ${ }^{55,99}$ In a study by Nader-Sepahi and 
colleagues, ${ }^{99}$ the mean aspect ratio was 2.70 for ruptured aneurysms, compared with 1.8 for unruptured aneurysms. It is currently accepted that the risk of hemorrhage is high when the aspect ratio is greater than $3 .^{78}$

Active cigarette smoking has been shown to be an important risk factor for aneurysm growth ${ }^{39,66}$ and therefore should be considered in the decision whether to treat or watch an aneurysm. ${ }^{39}$ Patients should also be strongly advised to quit smoking. Although female sex has been cited in 1 article as a potential risk factor for aneurysm growth, ${ }^{66}$ more evidence is needed before including this factor in the decision-making algorithm for these lesions. Hypertension is the most obvious risk factor for aneurysm growth and rupture in the brain and elsewhere in the body. ${ }^{39,101,106} \mathrm{~A}$ recent article that linked arterial hypertension to cerebral aneurysm growth and rupture strongly recommended that hypertension be considered when treatment indications for small unruptured aneurysms are discussed. ${ }^{39}$

The ISUIA showed that patients with prior SAH have a greater risk of rupture of intracranial aneurysms. Similarly, a family history of SAH is a significant risk factor for aneurysm growth and ruprture. ${ }^{27,94,126}$ In a study that followed 130 patients with unruptured aneurysms using serial magnetic resonance angiography, a family history of SAH was found to be an independent risk factor for aneurysm growth. ${ }^{94}$

According to the recommendations of the Stroke Council of the American Heart Association, any changes in aneurysm size or configuration should lead to special consideration for treatment.

A recent study showed that growth and rupture risks of aneurysms in the autosomal dominant polycystic kidney disease group are not higher than those in the general population. ${ }^{59}$

Finally the patient's age (and life expectancy) is a crucial factor when discussing treatment indications. A defined cutoff age, however, has not been determined. Mitchell et al. ${ }^{93}$ concluded in their study that patients with remaining life expectancy of less than 20 years should be informed that from a statistical point of view the benefits of treatment do not outweigh the risks. Additional data are necessary to more clearly determine the impact of age and establishment of a potential age cutoff. An absolute cutoff age is unlikely to be established as many other factors play into the decision-making process.

Treatment decisions should obviously be individualized to every patient, and the choice between surgical clip placement and endovascular treatment should take into consideration the configuration and location of the aneurysm, as well as the patient's age and preferences. In patients managed conservatively, periodic follow-up (every 6-12 months) with noninvasive imaging studies (MR angiography or CT angiography) is recommended .

Based on the current evidence in the literature, the recommendations of the Stroke Council of the American Heart Association, and our institutional experience with aneurysms, we suggest the following paradigm in the decision-making process with respect to incidentally discovered intracranial aneurysms (Fig. 1).

We grouped risk factors of growth and rupture of intracranial aneurysms into 2 categories:
The Type A category represents risk factors that favor intervention over observation. These factors include active smoking, arterial hypertension, posterior circulation aneurysm, prior SAH, history of familial SAH, and an aspect ratio greater than 3 .

The Type B category represents risk factors that warrant strong consideration for treatment regardless of the size of the aneurysm. These include young patient age, change in the size or configuration of the aneurysm, and the presence of multiple, multilobed, or symptomatic aneurysms.

We recommend that aneurysms larger than $7 \mathrm{~mm}$ in diameter be treated because of their propensity to rupture, except in older patients and those with significant medical comorbidities and short life expectancy. Aneurysms less than $5 \mathrm{~mm}$ in diameter should only be treated in the presence of 2 or more Type A risk factors or in the presence of any of the Type B risk factors. Finally, aneurysms that are 5-7 $\mathrm{mm}$ in diameter should be treated if any risk factor (Type A or Type B) is present.

\section{Arteriovenous Malformations}

Brain AVMs are the leading cause of intracerebral hemorrhage in the young population. They are responsible for $3 \%$ of strokes in young adults and $9 \%$ of SAHs. ${ }^{8}$ The prevalence of these lesions is 1 per 1000 adults, ${ }^{144}$ and their incidence is 1 per 100,000 per year. The most common manifestation of an AVM is an intracranial hemorrhage, accounting for as many as 50\% of initial presentations. ${ }^{145}$ AVMs may also cause headaches, seizures, or focal neurological deficits. More recently, however, more AVMs are being incidentally discovered with noninvasive imaging techniques. At present there is a paucity of high-quality evidence in the literature. Consequently, the optimal management of these lesions is not clear, and neurosurgeons are left to make difficult clinical decisions with respect to the management of incidental brain AVMs.

\section{Natural History}

The most dreaded complication of an AVM is an intracerebral hemorrhage. The annual rate of hemorrhage varies widely and depends on the number of risk factors. In most series, a previous hemorrhage, a central location, a deep venous drainage, and the presence of intranidal aneurysms greatly increase the risk of future hemorrhage..$^{30,38,132,134}$ In unruptured lesions not deeply located and without deep venous drainage, the annual risk of bleeding is as low as $0.9 \%$, according to the Columbia AVM database. ${ }^{132}$ Conversely, in AVMs with all the previously mentioned risk factors, the annual rate of hemorrhage can reach $34.4 \%$. The strongest risk factor for subsequent AVM bleeding is an intracranial hemorrhage at initial presentation. ${ }^{132}$ A small AVM size was also associated with hemorrhage in 3 series, ${ }^{35,46,132}$ but several other studies failed to demonstrate this association. ${ }^{30,48}$ Furthermore, Stefani et al. ${ }^{134}$ reported that large and deep-seated AVMs were more prone to hemorrhage during prospective follow-up of 390 patients with brain AVMs at the University of Toronto (Toronto Brain Vascular Malfor- 
N. Chalouhi et al.

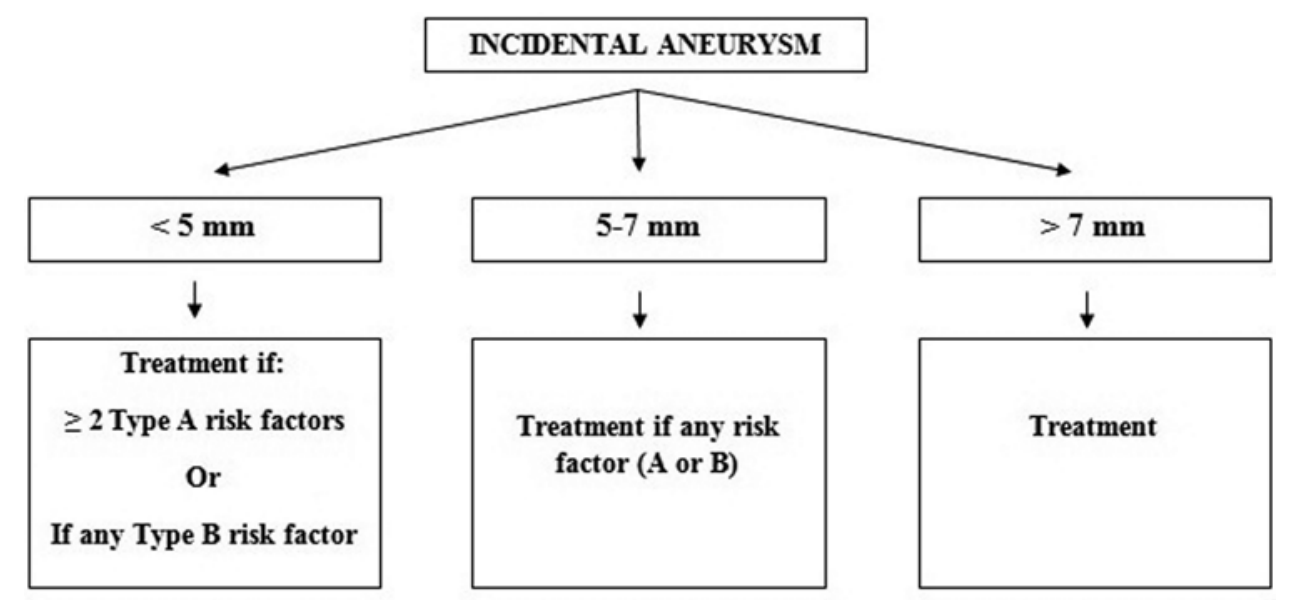

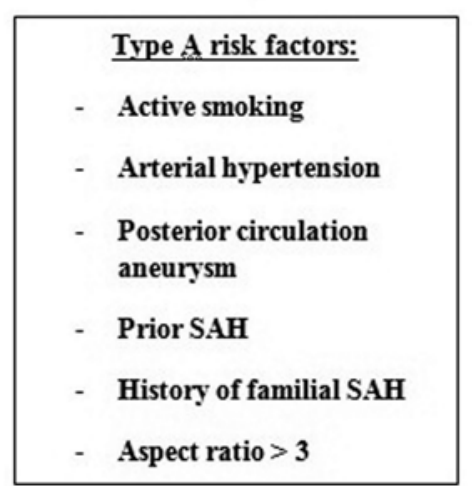

Fig. 1. Management of incidental aneurysms.

mation Study Group). Studies have also shown that the presence of venous stenosis on angiography increases the rate of intracranial hemorrhage. ${ }^{85,104}$ It is estimated that for unruptured AVMs, regardless of the other risk factors, the average annual rate of bleeding ranges from $2 \%$ to 4\%..$^{13,107}$ Kondziolka et al. ${ }^{73}$ proposed the following formula taking into account the patient's age to estimate the lifetime risk of hemorrhage for an AVM:

risk of hemorrhage $=1-(\text { risk of no hemorrhage })^{\text {expected years of }}$ remaining life.

Based on a $3 \%$ annual risk of hemorrhage, Brown ${ }^{28}$ proposed a simple and reasonable approximation of the above formula:

lifetime risk of hemorrhage $=105-$ patient's age in years.

It is also estimated that the average annual case fatality rate is around $1 \%$ for AVMs. ${ }^{132} \mathrm{~A}$ hemorrhage from the AVM remains a deadly and extremely morbid event; the mortality rate is around $10 \%-15 \%$ and the morbidity rate can be as high as $53-81 \% .{ }^{41}$ Such morbidity and mortality rates could prompt neurosurgeons to offer treatment to all incidentally discovered AVMs. However, the low rate of hemorrhage of unruptured AVMs and the mild clinical syndrome from such rupture reported in the Columbia database raise doubt about the benefit of interventional therapy for AVMs that have not been associated with any hemorrhage. ${ }^{133}$ The results of the Columbia database provided impetus for ARUBA (A Randomized Trial of Unruptured Brain AVMs). ${ }^{131}$ This ongoing project is a prospective, multicenter, randomized, controlled trial

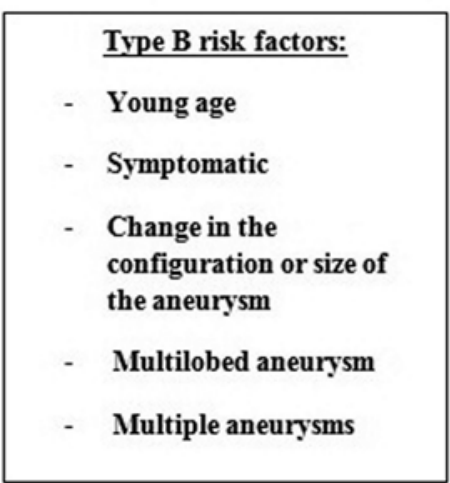

that enrolls 800 patients with unruptured brain AVMs and aims to determine whether medical management improves long-term outcomes of patients with unruptured AVMs compared with interventional therapy.

At present, there are limited data in the literature about the natural history of AVMs. Additional information may become available from studies such as ARUBA.

\section{Management of Incidentally Discovered AVMs}

The management of incidentally discovered AVMs aims to prevent an intracranial hemorrhage. Arteriovenous malformations are classically treated by open surgery, radiosurgery, endovascular techniques, or a combination of the three. It is not clear, however, if an intervention improves the outcome of incidentally discovered AVMs. A recent study by Wedderburn et al. ${ }^{45}$ in Scotland compared the 3-year outcome for adults who received interventional treatment for their unruptured AVMs (63 patients) with those who did not (51 patients). They found no difference in the functional outcome between the 2 groups. Moreover, interventional treatment was found to be an independent predictor of progression to poor outcome, as was AVM size. The results of this study should be interpreted with much caution for 2 main reasons. First, the 2 groups were not comparable at baseline, which means that confounding factors were not neutralized and have probably biased the study. Second, the follow-up was limited to only 3 years, which greatly underestimates any long-term benefits from interventional treatment and partly explains why the 2 


\section{Incidental vascular abnormalities}

groups had comparable outcomes. Another study by Lawton et al..$^{79}$ compared the benefits from resection in 224 patients with ruptured or unruptured AVMs. The condition of patients with ruptured AVMs improved after surgery, whereas patients with unruptured AVMs were susceptible to slight worsening of their neurological status. However, again the mean follow-up period was just 1.3 years, so no meaningful conclusions can be drawn from this study regarding the benefit of treatment. A recent analysis of the Columbia database showed that the initiation of any invasive treatment strategy was associated with a 3-fold increased risk of AVM hemorrhage and an increased risk of clinical impairment, raising questions about the benefit of treating unruptured AVMs. ${ }^{133}$ Conversely, in a study involving 623 patients harboring AVMs, with a median follow-up of 11.9 years, Laakso et al..$^{75}$ found that active treatment of these lesions improved outcome and that even partial treatment enhances survival, but this benefit is not apparent until 6 years after the intervention. This may explain why the previously cited studies reported no benefit from treatment of unruptured AVMs. We hope that ARUBA, discussed above, will help solve the dilemma, although we are concerned that the planned follow-up period may be too short.

With the recent advances in endovascular techniques, embolization has become a safe and effective primary treatment modality for AVMs. In a series of 387 patients with a brain AVM, Valavanis and Yasargil ${ }^{142}$ achieved a $40 \%$ angiographic cure with morbidity and mortality rates as low as $1 \%$. Endovascular embolization can completely cure an AVM, especially small lesions with limited arterial feeders, which were reported to have a cure rate close to $85 \%$ according to a recent series. ${ }^{12}$ It can also be used before surgery to decrease the size of the nidus and occlude surgically inaccessible feeders, reducing the amount of blood loss and shortening operative time..$^{29,87}$ In addition, embolization decreases the target size of the AVM; this reduction in target size has been associated with less morbidity and higher cure rates following radiosurgery, ${ }^{45}$ although it remains the subject of controversy. Finally, embolization can be palliative for patients with large nonresectable AVMs, intractable seizures, or progressive neurological deficits. ${ }^{42,82}$ A variety of embolic materials are currently used for the treatment of AVMs. $\mathrm{N}$-butyl cyanoacrylate (NBCA) and Onyx (ev3, Inc.) are nonabsorbable embolic agents that can achieve complete obliteration of an AVM. Due to its nonadhesive nature, Onyx allows longer, slower, and more controlled injections with subsequent embolization of a larger percentage of the AVM from a single catheter position. In a very recent article, Saatci et al. ${ }^{21}$ reported achieving complete obliteration in more than $50 \%$ of brain AVMs using prolonged intranidal Onyx injection. The authors concluded that this technique leads to higher rates of anatomical cures than previously reported with other embolic agents. In addition, the more effective intranidal penetration of the embolic agent with this technique allows high-grade AVMs to be made radiosurgically treatable.

In radiosurgical treatment of AVMs, the goal is obliteration of the vessels in the nidus. It is known to provide high cure rates and low morbidity rates, especially in small lesions. ${ }^{88,136}$ It is also useful in treating small deeply located AVMs that are otherwise challenging to surgical treatment or embolization. ${ }^{11,89}$ Maruyama et al ${ }^{89}$ reported a $66 \%$ obliteration rate for brainstem AVMs after radiosurgery (at 3-year follow-up). However, as the size of the AVM increases, the cure rate decreases and the complication rate increases. ${ }^{33,47,105}$ Another major disadvantage of radiosurgery is the risk of hemorrhage until the AVM is totally obliterated..$^{103,111}$ In a retrospective study of 500 patients with AVMs who were treated with Gamma Knife surgery, Maruyama et al. ${ }^{88}$ reported that 23 patients had a hemorrhage during the first 2 years following radiosurgery, and 6 patients had a hemorrhage even after angiographic obliteration. The risk of hemorrhage declined by $54 \%$ after 2 years and by $88 \%$ after obliteration of the lesion. In a recently published article, Blamek and colleague ${ }^{26}$ reported that annual hemorrhage rates after radiosurgery were $3.4 \%$ and $1.1 \%$ during the 1 st and 2 nd year of follow-up, respectively. The authors also concluded that a 3-year follow-up period is required to accurately assess the outcome after radiosurgery for brain AVMs.

Surgical excision of AVMs has long been considered the mainstay of treatment, with the advantage of completely removing the lesions. However, potential morbidity and mortality rates associated with the procedure warrant careful patient selection especially for incidentally discovered AVMs. The Spetzler-Martin classification takes into account the AVM size, eloquence of the adjacent brain, and the pattern of venous drainage of the AVM to estimate the surgical risk. ${ }^{129}$ The initial classification (1986) included 5 categories ${ }^{129}$ (Table 1). In a prospective evaluation of the classification system, morbidity rates for Grades I, II, and III were $0 \%$, increasing to $21.9 \%$ in patients with Grade IV and $16.7 \%$ in patients with Grade V AVMs. ${ }^{50}$ Similarly, Heros and $\mathrm{Tu}^{53}$ reported good surgical results in $100 \%, 94.3 \%, 88.6 \%, 61 \%$, and $28.6 \%$ of patients with Grade I, II, III, IV, and V AVMs, respectively. It is therefore clear that Grades I and II and even Grade III lesions (low-grade AVMs) can totally be excised with a low rate of observed morbidity. Conversely, Grade IV and V AVMs (high-grade AVMs) are associated with a high rate of complications, and surgery should therefore be avoided in patients with these lesions. A few studies have assessed the risk of hemorrhage of AVMs based on the Spetzler-Martin grade with conflicting results. A high annual risk of bleeding for high-grade AVMs (10.4\%) was

\section{TABLE 1: The Spetzler-Martin classification for AVMs}

\begin{tabular}{ll}
\hline \multicolumn{1}{c}{ Lesion Characteristics } & Points \\
\hline size & 1 \\
small $(<3 \mathrm{~cm})$ & 2 \\
medium $(3-6 \mathrm{~cm})$ & 3 \\
$\quad$ large $(>6 \mathrm{~cm})$ & 0 \\
eloquence of the adjacent brain & 1 \\
noneloquent & \\
eloquent & 0 \\
pattern of venous drainage & 1 \\
superficial only & \\
deep &
\end{tabular}


N. Chalouhi et al.

reported in a study by Jayaraman and coworkers. ${ }^{62}$ Elsewhere, the risk was found to be even lower (1.5\%) than that for all AVMs on average (3\%). ${ }^{51}$ In a recently published article, Spetzler and Ponce ${ }^{130}$ proposed a new classification for AVMs (2011) that consists of 3 classes: Spetzler-Martin Grades I and II AVMs were combined into Class A and Grades IV and V lesions into Class C; Grade III AVMs became Class B (Table 2). This was justified by the finding that surgical outcomes in 1476 cases from 7 surgical series were similar for Grades I and II AVMs (Class A) and for Grades IV and V AVMs (Class C). ${ }^{130}$ The new classification system also offers a paradigm for management of AVMs; surgical excision is recommended for Class A, multimodality therapy for Class B, and observation for Class C. Treatment of Class C AVMs is only recommended in the presence of recurrent hemorrhages, progressive neurological deficits, steal-related symptoms, and AVM-related aneurysms. ${ }^{130}$

In our institution, we perform endovascular embolization for some Grade IV AVMs even in the absence of the previously cited factors, especially in cases involving young patients. Embolization can safely decrease the size and the grade of the lesion, allowing for surgical excision or radiosurgery. ${ }^{84,121,148,149}$ Blackburn et al. ${ }^{25}$ recently evaluated endovascular therapy followed by radiosurgery in 21 patients with high-grade AVMs (12 lesions were Spetzler-Martin Grade IV or V). Interestingly, they found an obliteration rate close to $80 \%$ and a major neurological complications rate as low as $0 \%$. In the previously discussed study by Saatci et al., ${ }^{121}$ which involved 350 patients with brain AVMs, including high-grade lesions, the authors reported complete obliteration by endovascular means in $50 \%$ of the population, with $38 \%$ and $6 \%$ of the patients referred to radiosurgery and surgical excision, respectively. It is also well known that the Spetzler-Martin classification is not applicable for embolization procedures because deep venous drainage is not associated with increased risk of complications for this treatment modality. Furthermore the classification system does not take into account important factors for embolization like the number of vessels feeding into the AVM and the presence of fistulous components. ${ }^{40}$

Based on the current evidence in the literature and our experience, we suggest the following algorithm (Table 3).

We recommend surgical excision for Spetzler-Martin Grade I and II AVMs. Grade III AVMs should be treated with a combination of surgery, endovascular techniques, and radiosurgery. Grade IV AVMs should be strongly considered for endovascular therapy followed whenever

TABLE 2: The 3-tier classification of cerebral AVMs

\begin{tabular}{cll}
\hline Spetzler-Martin Class & Grade & \multicolumn{1}{c}{ Management } \\
\hline A & I \& I & resection \\
B & III & multimodality treatment \\
C & IV \& V & no treatment \\
\hline
\end{tabular}

\footnotetext{
* Exceptions for treatment of Class C AVMs include cases characterized by recurrent hemorrhages, progressive neurological deficits, and steal-related symptoms, as well as AVM-related aneurysms.
}

TABLE 3: Management of incidental AVMs

\begin{tabular}{cl}
\hline $\begin{array}{c}\text { Spetzler-Martin } \\
\text { Grade }\end{array}$ & \multicolumn{1}{c}{ Management } \\
\hline I \& II & surgery \\
III & multimodality treatment \\
IV & endovascular treatment followed by surgery/radiosur- \\
& gery, or observation \\
V & observation or endovascular treatment followed by \\
& radiosurgery (especially for young patients) \\
\hline
\end{tabular}

possible by surgery or radiosurgery. Observation is also an option in the latter group. Finally, we recommend observation in cases of Grade V AVMs because of the high morbidity rate associated with treatment. In some cases, especially those involving young patients, Grade $\mathrm{V}$ AVMs can be considered for endovascular therapy followed by radiosurgery.

\section{Cavernous Angiomas}

Cavernous angiomas, more commonly known as cavernomas, are low-flow vascular abnormalities of the brain composed of clusters of dilated, thin-walled capillaries filled with thrombus. ${ }^{44}$ These lesions account for $15 \%$ of all vascular malformations ${ }^{18,86}$ and have an estimated prevalence approaching $0.6 \%$ in the general population. ${ }^{18,37,120}$ Up to $50 \%$ of CAs are familial ${ }^{77}$ and follow an autosomal dominant pattern of inheritance linked to the CCM1, $C C M 2$, and $C C M 3$ genes on $7 \mathrm{q}, 7 \mathrm{p}$, and $3 \mathrm{q}$, respectively. ${ }^{22,61,77}$ Patients with familial CAs typically harbor multiple lesions, unlike those with a sporadic form who usually present with a single lesion. ${ }^{77,152}$ Cavernous angiomas are typically located supratentorially; brainstem lesions account only for $8 \%-22 \%$ of all cases.

Patients with CAs usually present in the 4th or 5th decade of life, although in $25 \%$ of cases, patients present in childhood. ${ }^{98}$ Depending on their location, the lesions can manifest with seizures, headaches, progressive neurological deficits, or intracranial hemorrhage. The most common presentation in patients with supratentorial CA is a new-onset seizure (40\%-70\% of cases). ${ }^{4,71,151}$ Seizures are due to recurrent microhemorrhages and hemosiderin deposition in the perilesional area. ${ }^{152}$ Headaches are also a common presentation and occur in $30 \%-50 \%$ of cases. ${ }^{74,151,152}$ Infratentorial CAs are rarely clinically silent and typically produce progressive neurological deficits. ${ }^{52,143}$ Intracranial hemorrhages are seen in both supratentorial and infratentorial lesions and are typically mild in severity, but severe and fatal hemorrhages do occur. With the increased use of MR imaging for brain imaging, it is now estimated that almost $40 \%$ of CAs that are identified represent incidental findings. ${ }^{18}$

Cavernous angiomas are known as angiographically occult vascular malformations because they do not appear on angiography, which therefore has little value in the diagnosis or management of these lesions except for detecting the presence of an associated atypical venous drainage. ${ }^{24}$ Magnetic resonance imaging is the most sensitive and specific imaging modality for the diagnosis and 
follow-up of CAs. ${ }^{57,116}$ Typically, the lesions appear as areas of mixed signal intensity on T1- and T2-weighted images and are surrounded by a peripheral area of hypointensity (representing a hemosiderin ring) on T2-weighted images. ${ }^{119}$ According to recent reports, the highly sensitive T2-weighted gradient-echo imaging has become the gold standard MR imaging sequence for visualization of CAs. ${ }^{31,81}$

\section{Natural History and Management of Incidentally Discovered CAs}

The annual rate of symptomatic hemorrhage from a CA ranges from $0.7 \%$ to $6 \%$ according to multiple studies and varies with a number of factors. ${ }^{76,113,120,152}$ The risk of significant bleeding is higher in patients with a prior history of hemorrhage. ${ }^{6,72}$ In a study involving 122 patients with CAs, Kondziolka et al. ${ }^{72}$ reported an annual hemorrhage rate of $0.6 \%$ in patients with no hemorrhagic presentation versus $4.5 \%$ for patients with hemorrhagic presentation. It is worth noting that the risk of rebleeding is particularly high in the 2 years following the initial hemorrhage but seems to significantly decrease thereafter. This phenomenon is known as "temporal clustering" and has been reported in several series. ${ }^{16,143}$ Deeply located CAs, especially those in the brainstem, have been found to carry a worse prognosis than superficial lesions. ${ }^{112}$ Porter et al. ${ }^{112}$ reported that the risk of bleeding for infratentorial CAs is $3.8 \%$ compared with $0.4 \%$ for supratentorial CAs. Female sex also appears to negatively impact the outcome for patients with CAs. ${ }^{6,113}$ Seizures and a familial form have been proposed as potential risk factors for hemorrhage, but there is not enough evidence in the literature to support this hypothesis.

The treatment of symptomatic CAs is image-guided resection. If a DVA is associated, it is recommended not to excise the DVA, as doing so would pose an unnecessary risk of venous infarction. ${ }^{3}$ Surgery is classically performed in patients with repetitive episodes of hemorrhage, intractable seizures, and progressive neurological deficits, especially when the CA is located in noneloquent areas of the brain. ${ }^{24,36,115}$ Conversely, in deep and eloquent areas, the risk of complications is substantial and the threshold for surgery is even higher. ${ }^{10,23,135}$ There is a recent tendency in some institutions to extend surgical indications to mildly symptomatic CAs, even in the brainstem. In a recent study involving 300 patients with surgically treated brainstem cavernomas, Abla et al. ${ }^{2}$ reported that surgery markedly improved the risk of rehemorrhage and related symptoms. They concluded that surgery should be considered in patients with accessible lesions. However, new or worsening neurological symptoms developed in $53 \%$ of patients after the procedure, $36 \%$ had permanent new deficits, and perioperative complications developed in $28 \% .^{2}$ Due to the significant potential morbidity associated with resection of CAs in eloquent areas like the brainstem, we have adopted a more conservative approach. More evidence is needed to ascertain whether patients with mildly symptomatic but accessible brainstem CAs actually benefit from surgery.

Finally, the role of radiosurgery in the treatment of CAs is still controversial despite encouraging reports. In a recent study involving 68 patients with brainstem CAs treated with Gamma Knife surgery, Monaco et al. ${ }^{95}$ found that radiosurgery decreased the annual hemorrhage rate from $32 \%$ before treatment to $1.3 \%$ after 2 years of followup. However $11.8 \%$ of patients experienced new neurological deficits as a result of adverse radiation effects. Lunsford et al..$^{83}$ were also able to demonstrate that radiosurgery reduced the risk of bleeding from $32 \%$ to just $1 \%$ after 2 years of follow-up. The rate of morbidity was $13.5 \%$ in this series. There are concerns about the high risk of complications associated with radiosurgery for CAs, particularly in the brainstem and deep locations., ${ }^{9,69,95}$ It is also known, as discussed above, that the risk of bleeding of a CA significantly decreases by itself beyond 2 years after the initial hemorrhage. Consequently, the positive results associated with radiosurgery in the previously cited studies could simply reflect the natural history of these lesions. The utility of radiosurgery in the treatment of CAs remains unproven and continues to be a subject of debate.

Purely incidental CAs should be managed conservatively and followed with yearly MR imaging. We recommend treating cavernous angiomas only in the following situations: intractable seizures, progressive significant neurological deficit, after the first clinically significant hemorrhage in noneloquent areas, and after the second clinically significant hemorrhage in eloquent areas including the brainstem.

\section{Developmental Venous Anomalies}

Developmental venous anomalies, formerly known as venous angiomas, are enlarged venous vessels that drain into a large-caliber vein with a characteristic appearance of caput medusa on angiography. They are congenital malformations of the brain that are viewed as a normal variant of the cerebral venous system. Their prevalence is $2.5 \%$ according to autopsy studies. ${ }^{43,125}$ Developmental venous anomalies are the most commonly diagnosed intracranial vascular malformation and are typically discovered incidentally on brain MR imaging studies or CT scans. ${ }^{139}$ They are associated with a CA in $13 \%-18 \%$ of cases, ${ }^{124,139}$ and it is thought that there is a causative link between these 2 lesions. It has been postulated that the recurrent microhemorrhages from a DVA induce angiogenesis in the surrounding brain, leading to CA formation. ${ }^{110}$

Developmental venous anomalies have a benign natural history with an extremely low morbidity rate and a mortality rate of $0 \% .91,100$ The annual risk of hemorrhage is negligible $(0.25 \%-0.34 \%),{ }^{37,91}$ and it is thought that a hemorrhage in the setting of a DVA is due to an associated CA. ${ }^{117}$ Nevertheless, DVA thrombosis can lead to a venous infarct with a secondary hemorrhagic transformation, although this remains a rare event..$^{90}$ No relationship has been established to date between DVAs and headaches or seizures..$^{96,137}$

A DVA is primarily visualized on MR images as a signal-void linear structure especially on T2-weighted sequences. ${ }^{140}$ Magnetic resonance imaging also offers the possibility of detecting an associated cavernoma. Contrast-enhanced MR imaging is the sequence of choice and shows the classic caput medusa appearance. ${ }^{140}$ Similar 
findings are seen on contrast-enhanced CT. Angiography is performed only in patients with an ischemic or hemorrhagic presentation and in those in whom an AVM should be ruled out.

Surgical obliteration of a DVA can lead to venous thrombosis, venous congestion, and infarct with a secondary hemorrhagic conversion.,128 This is due to the fact that a DVA drains normal brain tissue. Developmental venous anomalies should always be left untreated, even when associated with a CA. ${ }^{1}$ Given their benign natural history, DVAs do not require follow-up imaging studies.

\section{Capillary Telangiectasias}

Capillary telangiectasias are dilated thin-walled capillaries surrounded by normal brain parenchyma and associated with other vascular abnormalities. ${ }^{15}$ They are relatively common and account for $4 \%-12 \%$ of all vascular malformations. ${ }^{127}$ Capillary telangiectasias are incidental findings on imaging studies and are frequently misdiagnosed as glial tumors. Patients typically remain typically asymptomatic throughout life, although the lesions may occasionally cause seizures, vertigo, cranial nerve dysfunction, visual changes, and dizziness. ${ }^{80,138}$ In a recent study, Sayama et al. ${ }^{127}$ reported that $28.6 \%$ of large capillary telangiectasias $(>1 \mathrm{~cm})$ were symptomatic, whereas none of the small ones were.

Capillary telangiectasias are visualized as small enhancing lesions on contrast-enhanced MR imaging sequences and demonstrate a signal intensity loss on gradient-echo sequences. ${ }^{32}$ They are angiographically occult and are not usually seen on CT scan.

Capillary telangiectasias are benign lesions that do not require any treatment or follow-up.

\section{Conclusions}

Incidentally discovered intracranial vascular abnormalities are increasingly coming to the attention of neurosurgeons with the ubiquitous availability of highquality, noninvasive imaging studies. Lesions such as intracranial aneurysms, AVMs, CAs, DVAs, and capillary telangiectasias may be incidentally discovered on brain imaging studies. Each pathological entity is associated with its own unique natural history, and management must be tailored to the type of lesion and individual circumstances of a given patient. In the present article we have attempted to provide an evidence-based resource to guide neurosurgeons in the management of these incidentally discovered intracranial vascular abnormalities. The quality and quantity of evidence, however, remains limited, and further studies are needed to elucidate the most appropriate management strategy in many situations.

\section{Disclosure}

The authors report no conflict of interest concerning the materials or methods used in this study or the findings specified in this paper.

Author contributions to the study and manuscript preparation include the following. Conception and design: Jabbour, Chalouhi. Acquisition of data: Chalouhi. Drafting the article: Jabbour. Criti- cally revising the article: Jabbour, Chalouhi, Dumont, Randazzo, Tjoumakaris, Gonzalez. Reviewed submitted version of manuscript: all authors. Approved the final version of the manuscript on behalf of all authors: Jabbour. Administrative/technical/material support: Chalouhi. Study supervision: Jabbour.

\section{References}

1. Abla AA, Lekovic GP, Turner J, de Oliveira JG, Porter R, Spetzler RF: Advances in the treatment and outcome of brain stem cavernous malformation surgery: a case series of 300 surgically treated patients. Neurosurgery [epub ahead of print], 2010

2. Abla AA, Lekovic GP, Turner JD, de Oliveira JG, Porter R, Spetzler RF: Advances in the treatment and outcome of brainstem cavernous malformation surgery: a single-center case series of 300 surgically treated patients. Neurosurgery 68: 403-415, 2011

3. Abla AA, Turner JD, Mitha AP, Lekovic G, Spetzler RF: Surgical approaches to brainstem cavernous malformations. Neurosurg Focus 29(3): E8, 2010

4. Acciarri N, Galassi E, Giulioni M, Pozzati E, Grasso V, Palandri $\mathrm{G}$, et al: Cavernous malformations of the central nervous system in the pediatric age group. Pediatr Neurosurg 45:81-104, 2009

5. Aghakhani N, Vaz G, David P, Parker F, Goffette P, Ozan A, et al: Surgical management of unruptured intracranial aneurysms that are inappropriate for endovascular treatment: experience based on two academic centers. Neurosurgery 62: 1227-1235, 2008

6. Aiba T, Tanaka R, Koike T, Kameyama S, Takeda N, Komata T: Natural history of intracranial cavernous malformations. J Neurosurg 83:56-59, 1995

7. Al-Shahi R, Fang JS, Lewis SC, Warlow CP: Prevalence of adults with brain arteriovenous malformations: a community based study in Scotland using capture-recapture analysis. J Neurol Neurosurg Psychiatry 73:547-551, 2002

8. Al-Shahi R, Warlow C: A systematic review of the frequency and prognosis of arteriovenous malformations of the brain in adults. Brain 124:1900-1926, 2001

9. Amin-Hanjani S, Ogilvy CS, Candia GJ, Lyons S, Chapman PH: Stereotactic radiosurgery for cavernous malformations: Kjellberg's experience with proton beam therapy in 98 cases at the Harvard Cyclotron. Neurosurgery 42:1229-1238, 1998

10. Amin-Hanjani S, Ogilvy CS, Ojemann RG, Crowell RM: Risks of surgical management for cavernous malformations of the nervous system. Neurosurgery 42:1220-1228, 1998

11. Andrade-Souza YM, Zadeh G, Scora D, Tsao MN, Schwartz ML: Radiosurgery for basal ganglia, internal capsule, and thalamus arteriovenous malformation: clinical outcome. Neurosurgery 56:56-64, 2005

12. Andreou A, Ioannidis I, Lalloo S, Nickolaos N, Byrne JV: Endovascular treatment of intracranial microarteriovenous malformations. Clinical article. J Neurosurg 109:1091-1097, 2008

13. ApSimon HT, Reef H, Phadke RV, Popovic EA: A populationbased study of brain arteriovenous malformation: long-term treatment outcomes. Stroke 33:2794-2800, 2002

14. Asari S, Ohmoto T: Natural history and risk factors of unruptured cerebral aneurysms. Clin Neurol Neurosurg 95:205214, 1993

15. Awad IA, Robinson JR Jr, Mohanty S, Estes ML: Mixed vascular malformations of the brain: clinical and pathogenetic considerations. Neurosurgery 33:179-188, 1993

16. Barker FG II, Amin-Hanjani S, Butler WE, Lyons S, Ojemann RG, Chapman PH, et al: Temporal clustering of hemorrhages from untreated cavernous malformations of the central nervous system. Neurosurgery 49:15-25, 2001

17. Barker FG II, Amin-Hanjani S, Butler WE, Ogilvy CS, Carter BS: In-hospital mortality and morbidity after surgical treatment 


\section{Incidental vascular abnormalities}

of unruptured intracranial aneurysms in the United States, 1996-2000: the effect of hospital and surgeon volume. Neurosurgery 52:995-1009, 2003

18. Batra S, Lin D, Recinos PF, Zhang J, Rigamonti D: Cavernous malformations: natural history, diagnosis and treatment. Nat Rev Neurol 5:659-670, 2009

19. Bederson JB, Awad IA, Wiebers DO, Piepgras D, Haley EC Jr, Brott $\mathrm{T}$, et al: Recommendations for the management of patients with unruptured intracranial aneurysms: a statement for healthcare professionals from the Stroke Council of the American Heart Association. Circulation 102:2300-2308, 2000

20. Benes V III, Mitchell P, Molyneux AJ, Renowden SA: Endovascular coiling in 131 patients with low complication rate justifies treating most unruptured intracranial aneurysms. Cen Eur Neurosurg 71:1-7, 2010

21. Berenstein A, Flamm ES, Kupersmith MJ: Unruptured intracranial aneurysms. N Engl J Med 340:1439-1442, 1999

22. Bergametti F, Denier C, Labauge P, Arnoult M, Boetto S, Clanet M, et al: Mutations within the programmed cell death 10 gene cause cerebral cavernous malformations. Am J Hum Genet 76:42-51, 2005

23. Bertalanffy H, Benes L, Miyazawa T, Alberti O, Siegel AM, Sure U: Cerebral cavernomas in the adult. Review of the literature and analysis of 72 surgically treated patients. Neurosurg Rev 25:1-55, 2002

24. Bertalanffy H, Kühn G, Scheremet R, Seeger W: Indications for surgery and prognosis in patients with cerebral cavernous angiomas. Neurol Med Chir (Tokyo) 32:659-666, 1992

25. Blackburn SL, Ashley WW Jr, Rich KM, Simpson JR, Drzymala RE, Ray WZ, et al: Combined endovascular embolization and stereotactic radiosurgery in the treatment of large arteriovenous malformations. Clinical article. J Neurosurg 114: $1758-1767,2011$

26. Blamek S, Tarnawski R, Miszczyk L: Linac-based Stereotactic Radiosurgery for Brain Arteriovenous Malformations. Clin Oncol (R Coll Radiol) 23:525-531, 2011

27. Broderick JP, Brown RD Jr, Sauerbeck L, Hornung R, Huston J III, Woo D, et al: Greater rupture risk for familial as compared to sporadic unruptured intracranial aneurysms. Stroke 40:1952-1957, 2009

28. Brown RD Jr: Simple risk predictions for arteriovenous malformation hemorrhage. Neurosurgery 46:1024, 2000

29. Brown RD Jr, Flemming KD, Meyer FB, Cloft HJ, Pollock BE, Link ML: Natural history, evaluation, and management of intracranial vascular malformations. Mayo Clin Proc 80: 269-281, 2005

30. Brown RD Jr, Wiebers DO, Forbes GS: Unruptured intracranial aneurysms and arteriovenous malformations: frequency of intracranial hemorrhage and relationship of lesions. J Neurosurg 73:859-863, 1990

31. Campbell PG, Jabbour P, Yadla S, Awad IA: Emerging clinical imaging techniques for cerebral cavernous malformations: a systematic review. Neurosurg Focus 29(3):E6, 2010

32. Castillo M, Morrison T, Shaw JA, Bouldin TW: MR imaging and histologic features of capillary telangiectasia of the basal ganglia. AJNR Am J Neuroradiol 22:1553-1555, 2001

33. Chang JH, Chang JW, Park YG, Chung SS: Factors related to complete occlusion of arteriovenous malformations after gamma knife radiosurgery. J Neurosurg 93 (Suppl 3):96-101, 2000

34. Connolly ES Jr, Mohr JP, Solomon RA: Unruptured intracranial aneurysms. N Engl J Med 340:1440-1442, 1999

35. Crawford PM, West CR, Chadwick DW, Shaw MD: Arteriovenous malformations of the brain: natural history in unoperated patients. J Neurol Neurosurg Psychiatry 49:1-10, 1986

36. D’Angelo VA, De Bonis C, Amoroso R, Cali A, D’Agruma L, Guarnieri V, et al: Supratentorial cerebral cavernous malformations: clinical, surgical, and genetic involvement. Neurosurg Focus 21(1):e9, 2006
37. Del Curling O Jr, Kelly DL Jr, Elster AD, Craven TE: An analysis of the natural history of cavernous angiomas. J Neurosurg 75:702-708, 1991

38. Duong DH, Young WL, Vang MC, Sciacca RR, Mast H, Koennecke $\mathrm{HC}$, et al: Feeding artery pressure and venous drainage pattern are primary determinants of hemorrhage from cerebral arteriovenous malformations. Stroke 29:1167-1176, 1998

39. Etminan N, Beseoglu K, Steiger HJ, Hänggi D: The impact of hypertension and nicotine on the size of ruptured intracranial aneurysms. J Neurol Neurosurg Psychiatry 82:4-7, 2011

40. Feliciano CE, de León-Berra R, Hernández-Gaitán MS, Rodríguez-Mercado R: A proposal for a new arteriovenous malformation grading scale for neuroendovascular procedures and literature review. P R Health Sci J 29:117-120, 2010

41. Fleetwood IG, Steinberg GK: Arteriovenous malformations. Lancet 359:863-873, 2002

42. Fox AJ, Girvin JP, Viñuela F, Drake CG: Rolandic arteriovenous malformations: improvement in limb function by IBC embolization. AJNR Am J Neuroradiol 6:575-582, 1985

43. Garner TB, Del Curling O Jr, Kelly DL Jr, Laster DW: The natural history of intracranial venous angiomas. J Neurosurg 75:715-722, 1991

44. Gault J, Sarin H, Awadallah NA, Shenkar R, Awad IA: Pathobiology of human cerebrovascular malformations: basic mechanisms and clinical relevance. Neurosurgery 55:1-17, 2004

45. Gobin YP, Laurent A, Merienne L, Schlienger M, Aymard A, Houdart E, et al: Treatment of brain arteriovenous malformations by embolization and radiosurgery. J Neurosurg 85: 19-28, 1996

46. Graf CJ, Perret GE, Torner JC: Bleeding from cerebral arteriovenous malformations as part of their natural history. $\mathbf{J}$ Neurosurg 58:331-337, 1983

47. Hadjipanayis CG, Levy EI, Niranjan A, Firlik AD, Kondziolka D, Flickinger JC, et al: Stereotactic radiosurgery for motor cortex region arteriovenous malformations. Neurosurgery 48:70-77, 2001

48. Halim AX, Johnston SC, Singh V, McCulloch CE, Bennett JP, Achrol AS, et al: Longitudinal risk of intracranial hemorrhage in patients with arteriovenous malformation of the brain within a defined population. Stroke 35:1697-1702, 2004

49. Hamada J, Morioka M, Yano S, Kai Y, Ushio Y: Incidence and early prognosis of aneurysmal subarachnoid hemorrhage in Kumamoto Prefecture, Japan. Neurosurgery 54:31-38, 2004

50. Hamilton MG, Spetzler RF: The prospective application of a grading system for arteriovenous malformations. Neurosurgery 34:2-7, 1994

51. Han PP, Ponce FA, Spetzler RF: Intention-to-treat analysis of Spetzler-Martin grades IV and V arteriovenous malformations: natural history and treatment paradigm. J Neurosurg 98:3-7, 2003

52. Hauck EF, Barnett SL, White JA, Samson D: Symptomatic brainstem cavernomas. Neurosurgery 64:61-71, 2009

53. Heros RC, Tu YK: Is surgical therapy needed for unruptured arteriovenous malformations? Neurology 37:279-286, 1987

54. Higashida RT, Lahue BJ, Torbey MT, Hopkins LN, Leip E, Hanley DF: Treatment of unruptured intracranial aneurysms: a nationwide assessment of effectiveness. AJNR Am J Neuroradiol 28:146-151, 2007

55. Hoh BL, Sistrom CL, Firment CS, Fautheree GL, Velat GJ, Whiting $\mathrm{JH}$, et al: Bottleneck factor and height-width ratio: association with ruptured aneurysms in patients with multiple cerebral aneurysms. Neurosurgery 61:716-723, 2007

56. Hop JW, Rinkel GJ, Algra A, van Gijn J: Case-fatality rates and functional outcome after subarachnoid hemorrhage: a systematic review. Stroke 28:660-664, 1997

57. Ide C, De Coene B, Baudrez V: MR features of cavernous angioma. JBR-BTR 83:320, 2000

58. International Study of Unruptured Intracranial Aneurysms Investigators: Unruptured intracranial aneurysms-risk of 
rupture and risks of surgical intervention. N Engl J Med 339: 1725-1733, 1998

59. Irazabal MV, Huston J III, Kubly V, Rossetti S, Sundsbak JL, Hogan MC, et al: Extended follow-up of unruptured intracranial aneurysms detected by presymptomatic screening in patients with autosomal dominant polycystic kidney disease. Clin J Am Soc Nephrol 6:1274-1285, 2011

60. Iwamoto H, Kiyohara Y, Fujishima M, Kato I, Nakayama K, Sueishi K, et al: Prevalence of intracranial saccular aneurysms in a Japanese community based on a consecutive autopsy series during a 30 -year observation period. The Hisayama study. Stroke 30:1390-1395, 1999

61. Jabbour P, Gault J, Awad IA: What genes can teach us about human cerebrovascular malformations. Clin Neurosurg 51:140-152, 2004

62. Jayaraman MV, Marcellus ML, Do HM, Chang SD, Rosenberg JK, Steinberg GK, et al: Hemorrhage rate in patients with Spetzler-Martin grades IV and V arteriovenous malformations: is treatment justified? Stroke 38:325-329, 2007

63. Jellinger K: Pathology of intracerebral hemorrhage. Zentralbl Neurochir 38:29-42, 1977

64. Johnston SC, Dudley RA, Gress DR, Ono L: Surgical and endovascular treatment of unruptured cerebral aneurysms at university hospitals. Neurology 52:1799-1805, 1999

65. Johnston SC, Zhao S, Dudley RA, Berman MF, Gress DR: Treatment of unruptured cerebral aneurysms in California. Stroke 32:597-605, 2001

66. Juvela S: Natural history of unruptured intracranial aneurysms: risks for aneurysm formation, growth, and rupture. Acta Neurochir Suppl 82:27-30, 2002

67. Juvela S: Prevalence of and risk factors for intracranial aneurysms. Lancet Neurol 10:595-597, 2011

68. Juvela S, Porras M, Poussa K: Natural history of unruptured intracranial aneurysms: probability of and risk factors for aneurysm rupture. J Neurosurg 93:379-387, 2000

69. Kim DG, Choe WJ, Paek SH, Chung HT, Kim IH, Han DH: Radiosurgery of intracranial cavernous malformations. Acta Neurochir (Wien) 144:869-878, 2002

70. King JT Jr, Berlin JA, Flamm ES: Morbidity and mortality from elective surgery for asymptomatic, unruptured, intracranial aneurysms: a meta-analysis. J Neurosurg 81:837-842, 1994

71. Kivelev J, Niemelä M, Kivisaari R, Dashti R, Laakso A, Hernesniemi J: Long-term outcome of patients with multiple cerebral cavernous malformations. Neurosurgery 65:450-455, 2009

72. Kondziolka D, Lunsford LD, Kestle JR: The natural history of cerebral cavernous malformations. J Neurosurg 83:820-824, 1995

73. Kondziolka D, McLaughlin MR, Kestle JR: Simple risk predictions for arteriovenous malformation hemorrhage. Neurosurgery 37:851-855, 1995

74. Kupersmith MJ, Kalish H, Epstein F, Yu G, Berenstein A, Woo H, et al: Natural history of brainstem cavernous malformations. Neurosurgery 48:47-54, 2001

75. Laakso A, Dashti R, Seppänen J, Juvela S, Väärt K, Niemelä M, et al: Long-term excess mortality in 623 patients with brain arteriovenous malformations. Neurosurgery 63:244-255, 2008

76. Labauge P, Brunereau L, Lévy C, Laberge S, Houtteville JP: The natural history of familial cerebral cavernomas: a retrospective MRI study of 40 patients. Neuroradiology 42:327332,2000

77. Laberge-le Couteulx S, Jung HH, Labauge P, Houtteville JP, Lescoat C, Cecillon M, et al: Truncating mutations in CCM1, encoding KRIT1, cause hereditary cavernous angiomas. Nat Genet 23:189-193, 1999

78. Lall RR, Eddleman CS, Bendok BR, Batjer HH: Unruptured intracranial aneurysms and the assessment of rupture risk based on anatomical and morphological factors: sifting through the sands of data. Neurosurg Focus 26(5):E2, 2009
79. Lawton MT, Du R, Tran MN, Achrol AS, McCulloch CE, Johnston SC, et al: Effect of presenting hemorrhage on outcome after microsurgical resection of brain arteriovenous malformations. Neurosurgery 56:485-493, 2005

80. Lee RR, Becher MW, Benson ML, Rigamonti D: Brain capillary telangiectasia: MR imaging appearance and clinicohistopathologic findings. Radiology 205:797-805, 1997

81. Lehnhardt FG, von Smekal U, Rückriem B, Stenzel W, Neveling M, Heiss WD, et al: Value of gradient-echo magnetic resonance imaging in the diagnosis of familial cerebral cavernous malformation. Arch Neurol 62:653-658, 2005

82. Luessenhop AJ, Mujica PH: Embolization of segments of the circle of Willis and adjacent branches for management of certain inoperable cerebral arteriovenous malformations. J Neurosurg 54:573-582, 1981

83. Lunsford LD, Khan AA, Niranjan A, Kano H, Flickinger JC, Kondziolka D: Stereotactic radiosurgery for symptomatic solitary cerebral cavernous malformations considered high risk for resection. Clinical article. J Neurosurg 113:23-29, 2010

84. Lv X, Wu Z, Jiang C, Li Y, Yang X, Zhang Y, et al: Complication risk of endovascular embolization for cerebral arteriovenous malformation. Eur J Radiol [epub ahead of print], 2010

85. Mansmann U, Meisel J, Brock M, Rodesch G, Alvarez H, Lasjaunias P: Factors associated with intracranial hemorrhage in cases of cerebral arteriovenous malformation. Neurosurgery 46:272-281, 2000

86. Maraire JN, Awad IA: Intracranial cavernous malformations: lesion behavior and management strategies. Neurosurgery 37:591-605, 1995

87. Martin NA, Khanna R, Doberstein C, Bentson J: Therapeutic embolization of arteriovenous malformations: the case for and against. Clin Neurosurg 46:295-318, 2000

88. Maruyama K, Kawahara N, Shin M, Tago M, Kishimoto J, Kurita $\mathrm{H}$, et al: The risk of hemorrhage after radiosurgery for cerebral arteriovenous malformations. N Engl J Med 352: 146-153, 2005

89. Maruyama K, Kondziolka D, Niranjan A, Flickinger JC, Lunsford LD: Stereotactic radiosurgery for brainstem arteriovenous malformations: factors affecting outcome. J Neurosurg 100:407-413, 2004

90. Masson C, Godefroy O, Leclerc X, Colombani JM, Leys D: Cerebral venous infarction following thrombosis of the draining vein of a venous angioma (developmental abnormality). Cerebrovasc Dis 10:235-238, 2000

91. McLaughlin MR, Kondziolka D, Flickinger JC, Lunsford S, Lunsford LD: The prospective natural history of cerebral venous malformations. Neurosurgery 43:195-201, 1998

92. Menghini VV, Brown RD Jr, Sicks JD, O'Fallon WM, Wiebers DO: Incidence and prevalence of intracranial aneurysms and hemorrhage in Olmsted County, Minnesota, 1965 to 1995. Neurology 51:405-411, 1998

93. Mitchell P, Gholkar A, Vindlacheruvu RR, Mendelow AD: Unruptured intracranial aneurysms: benign curiosity or ticking bomb? Lancet Neurol 3:85-92, 2004

94. Miyazawa N, Akiyama I, Yamagata Z: Risk factors for growth of unruptured intracranial aneurysms: follow-up study by serial 0.5-T magnetic resonance angiography. Neurosurgery 58:1047-1053, 2006

95. Monaco EA, Khan AA, Niranjan A, Kano H, Grandhi R, Kondziolka D, et al: Stereotactic radiosurgery for the treatment of symptomatic brainstem cavernous malformations. Neurosurg Focus 29(3):E11, 2010

96. Morioka T, Hashiguchi K, Nagata S, Miyagi Y, Yoshida F, Mihara F, et al: Epileptogenicity of supratentorial medullary venous malformation. Epilepsia 47:365-370, 2006

97. Moroi J, Hadeishi H, Suzuki A, Yasui N: Morbidity and mortality from surgical treatment of unruptured cerebral aneurysms at Research Institute for Brain and Blood Vessels-Akita. Neurosurgery 56:224-231, 2005 
98. Mottolese C, Hermier M, Stan H, Jouvet A, Saint-Pierre G, Froment JC, et al: Central nervous system cavernomas in the pediatric age group. Neurosurg Rev 24:55-73, 2001

99. Nader-Sepahi A, Casimiro M, Sen J, Kitchen ND: Is aspect ratio a reliable predictor of intracranial aneurysm rupture? Neurosurgery 54:1343-1348, 2004

100. Naff NJ, Wemmer J, Hoenig-Rigamonti K, Rigamonti DR: A longitudinal study of patients with venous malformations: documentation of a negligible hemorrhage risk and benign natural history. Neurology 50:1709-1714, 1998

101. Nahed BV, DiLuna ML, Morgan T, Ocal E, Hawkins AA, Ozduman K, et al: Hypertension, age, and location predict rupture of small intracranial aneurysms. Neurosurgery 57: 676-683, 2005

102. Nakagawa T, Hashi K: The incidence and treatment of asymptomatic, unruptured cerebral aneurysms. J Neurosurg 80:217223, 1994

103. Nataf F, Ghossoub M, Schlienger M, Moussa R, Meder JF, Roux FX: Bleeding after radiosurgery for cerebral arteriovenous malformations. Neurosurgery 55:298-306, 2004

104. Nataf F, Meder JF, Roux FX, Blustajn J, Merienne L, Merland $\mathrm{JJ}$, et al: Angioarchitecture associated with haemorrhage in cerebral arteriovenous malformations: a prognostic statistical model. Neuroradiology 39:52-58, 1997

105. Nataf F, Merienne L, Schlienger M, Lefkopoulos D, Meder JF, Touboul E, et al: [Cerebral arteriovenous malformations treated by radiosurgery: a series of 705 cases.] Neurochirurgie 47 (2-3 Pt 2):268-282, 2001 (Fr)

106. Ohashi Y, Horikoshi T, Sugita M, Yagishita T, Nukui H: Size of cerebral aneurysms and related factors in patients with subarachnoid hemorrhage. Surg Neurol 61:239-247, 2004

107. Ondra SL, Troupp H, George ED, Schwab K: The natural history of symptomatic arteriovenous malformations of the brain: a 24-year follow-up assessment. J Neurosurg 73:387-391, 1990

108. Peerless SJ, Hernesniemi JA, Gutman FB, Drake CG: Early surgery for ruptured vertebrobasilar aneurysms. J Neurosurg 80:643-649, 1994

109. Pereira-Filho AA, Pereira AG, Faria MB, Lima LC, Portuguez MW, Kraemer JL: Microsurgical clipping in forty patients with unruptured anterior cerebral circulation aneurysms: an investigation into cognitive outcome. Arq Neuropsiquiatr 68: 770-774, 2010

110. Perrini P, Lanzino G: The association of venous developmental anomalies and cavernous malformations: pathophysiological, diagnostic, and surgical considerations. Neurosurg Focus 21(1):e5, 2006

111. Pollock BE, Flickinger JC, Lunsford LD, Bissonette DJ, Kondziolka D: Hemorrhage risk after stereotactic radiosurgery of cerebral arteriovenous malformations. Neurosurgery 38:652-661, 1996

112. Porter PJ, Willinsky RA, Harper W, Wallace MC: Cerebral cavernous malformations: natural history and prognosis after clinical deterioration with or without hemorrhage. J Neurosurg 87:190-197, 1997

113. Porter RW, Detwiler PW, Spetzler RF, Lawton MT, Baskin JJ, Derksen PT, et al: Cavernous malformations of the brainstem: experience with 100 patients. J Neurosurg 90:50-58, 1999

114. Raaymakers TW, Rinkel GJ, Limburg M, Algra A: Mortality and morbidity of surgery for unruptured intracranial aneurysms: a meta-analysis. Stroke 29:1531-1538, 1998

115. Raychaudhuri R, Batjer HH, Awad IA: Intracranial cavernous angioma: a practical review of clinical and biological aspects. Surg Neurol 63:319-328, 2005

116. Rigamonti D, Johnson PC, Spetzler RF, Hadley MN, Drayer BP: Cavernous malformations and capillary telangiectasia: a spectrum within a single pathological entity. Neurosurgery 28:60-64, 1991

117. Rigamonti D, Spetzler RF, Medina M, Rigamonti K, Geckle
DS, Pappas C: Cerebral venous malformations. J Neurosurg 73:560-564, 1990

118. Rinkel GJ: Natural history, epidemiology and screening of unruptured intracranial aneurysms. J Neuroradiol 35:99-103, 2008

119. Rivera PP, Willinsky RA, Porter PJ: Intracranial cavernous malformations. Neuroimaging Clin N Am 13:27-40, 2003

120. Robinson JR, Awad IA, Little JR: Natural history of the cavernous angioma. J Neurosurg 75:709-714, 1991

121. Saatci I, Geyik S, Yavuz K, Cekirge HS: Endovascular treatment of brain arteriovenous malformations with prolonged intranidal Onyx injection technique: long-term results in 350 consecutive patients with completed endovascular treatment course. Clinical article. J Neurosurg 115:78-88, 2011

122. Sampei T, Mizuno M, Nakajima S, Suzuki A, Hadeishi H, Ishikawa $\mathrm{T}$, et al: [Clinical study of growing up aneurysms: report of 25 cases.] No Shinkei Geka 19:825-830, 1991 (Jpn)

123. Samson D, Batjer HH, Kopitnik TA Jr: Current results of the surgical management of aneurysms of the basilar apex. Neurosurgery 44:697-704, 1999

124. San Millán Ruíz D, Delavelle J, Yilmaz H, Gailloud P, Piovan E, Bertramello A, et al: Parenchymal abnormalities associated with developmental venous anomalies. Neuroradiology 49:987-995, 2007

125. Sarwar M, McCormick WF: Intracerebral venous angioma. Case report and review. Arch Neurol 35:323-325, 1978

126. Sato Y, Kakino S, Ogasawara K, Kubo Y, Kuroda H, Ogawa A: Rupture of a concomitant unruptured cerebral aneurysm within 2 weeks of surgical repair of a ruptured cerebral aneurysm-case report. Neurol Med Chir (Tokyo) 48:512-514, 2008

127. Sayama CM, Osborn AG, Chin SS, Couldwell WT: Capillary telangiectasias: clinical, radiographic, and histopathological features. Clinical article. J Neurosurg 113:709-714, 2010

128. Senegor M, Dohrmann GJ, Wollmann RL: Venous angiomas of the posterior fossa should be considered as anomalous venous drainage. Surg Neurol 19:26-32, 1983

129. Spetzler RF, Martin NA: A proposed grading system for arteriovenous malformations. J Neurosurg 65:476-483, 1986

130. Spetzler RF, Ponce FA: A 3-tier classification of cerebral arteriovenous malformations. Clinical article. J Neurosurg 114: 842-849, 2011

131. Stapf C: The rationale behind "A Randomized Trial of Unruptured Brain AVMs" (ARUBA). Acta Neurochir Suppl 107:83-85, 2010

132. Stapf C, Mast H, Sciacca RR, Choi JH, Khaw AV, Connolly ES, et al: Predictors of hemorrhage in patients with untreated brain arteriovenous malformation. Neurology 66:1350-1355, 2006

133. Stapf C, Mohr JP: Unruptured brain arteriovenous malformations should be treated conservatively: yes. Stroke 38:33083309, 2007

134. Stefani MA, Porter PJ, terBrugge KG, Montanera W, Willinsky RA, Wallace MC: Large and deep brain arteriovenous malformations are associated with risk of future hemorrhage. Stroke 33:1220-1224, 2002

135. Steinberg GK, Chang SD, Gewirtz RJ, Lopez JR: Microsurgical resection of brainstem, thalamic, and basal ganglia angiographically occult vascular malformations. Neurosurgery 46:260-271, 2000

136. Steiner L, Lindquist C, Adler JR, Torner JC, Alves W, Steiner M: Clinical outcome of radiosurgery for cerebral arteriovenous malformations. J Neurosurg 77:1-8, 1992

137. Striano S, Nocerino C, Striano P, Boccella P, Meo R, Bilo L, et al: Venous angiomas and epilepsy. Neurol Sci 21:151-155, 2000

138. Tang SC, Jeng JS, Liu HM, Yip PK: Diffuse capillary telangiectasia of the brain manifested as a slowly progressive course. Cerebrovasc Dis 15:140-142, 2003 
139. Töpper R, Jürgens E, Reul J, Thron A: Clinical significance of intracranial developmental venous anomalies. J Neurol Neurosurg Psychiatry 67:234-238, 1999

140. Truwit CL: Venous angioma of the brain: history, significance, and imaging findings. AJR Am J Roentgenol 159: 1299-1307, 1992

141. Tuffiash E, Tamargo RJ, Hillis AE: Craniotomy for treatment of unruptured aneurysms is not associated with long-term $\operatorname{cog}_{-}$ nitive dysfunction. Stroke 34:2195-2199, 2003

142. Valavanis A, Yaşargil MG: The endovascular treatment of brain arteriovenous malformations. Adv Tech Stand Neurosurg 24:131-214, 1998

143. Wang CC, Liu A, Zhang JT, Sun B, Zhao YL: Surgical management of brain-stem cavernous malformations: report of 137 cases. Surg Neurol 59:444-454, 2003

144. Weber F, Knopf H: Incidental findings in magnetic resonance imaging of the brains of healthy young men. J Neurol Sci 240:81-84, 2006

145. Wedderburn CJ, van Beijnum J, Bhattacharya JJ, Counsell CE, Papanastassiou V, Ritchie V, et al: Outcome after interventional or conservative management of unruptured brain arteriovenous malformations: a prospective, population-based cohort study. Lancet Neurol 7:223-230, 2008

146. Wermer MJ, van der Schaaf IC, Algra A, Rinkel GJ: Risk of rupture of unruptured intracranial aneurysms in relation to patient and aneurysm characteristics: an updated metaanalysis. Stroke 38:1404-1410, 2007
147. Wiebers DO, Whisnant JP, Huston J III, Meissner I, Brown RD Jr, Piepgras DG, et al: Unruptured intracranial aneurysms: natural history, clinical outcome, and risks of surgical and endovascular treatment. Lancet 362:103-110, 2003

148. Wikholm G: Role of transarterial embolization in the management of cerebral arteriovenous malformations. Acta Radiol Suppl 404:1-25, 1996

149. Wikholm G, Lundqvist C, Svendsen P: The Göteborg cohort of embolized cerebral arteriovenous malformations: a 6-year follow-up. Neurosurgery 49:799-806, 2001

150. Winn HR, Jane JA Sr, Taylor J, Kaiser D, Britz GW: Prevalence of asymptomatic incidental aneurysms: review of 4568 arteriograms. J Neurosurg 96:43-49, 2002

151. Xia C, Zhang R, Mao Y, Zhou L: Pediatric cavernous malformation in the central nervous system: report of 66 cases. Pediatr Neurosurg 45:105-113, 2009

152. Zabramski JM, Wascher TM, Spetzler RF, Johnson B, Golfinos J, Drayer BP, et al: The natural history of familial cavernous malformations: results of an ongoing study. $\mathbf{J}$ Neurosurg 80:422-432, 1994

Manuscript submitted August 7, 2011.

Accepted September 27, 2011.

Address correspondence to: Pascal Jabbour, M.D., 909 Walnut Street, 2nd floor, Philadelphia, Pennsylvania 19107. email: pascal. jabbour@jefferson.edu. 